\title{
CAN GENERAL PURPOSE TECHNOLOGY THEORY EXPLAIN ECONOMIC GROWTH? ELECTRICAL POWER AS A CASE STUDY
}

\author{
Cristiano Andrea Ristuccia \\ Trinity Hall \\ Cambridge, UK \\ Solomos Solomou \\ Faculty of Economics \\ University of Cambridge \\ Cambridge, UK
}

\begin{abstract}
Does the concept of General Purpose Technologies help explain periods of faster and slower productivity advance in economies? The paper develops a new comparative data set on the usage of electricity in the manufacturing sectors of the USA, Britain, France, Germany and Japan and proceeds to evaluate the hypothesis of a productivity bonus as postulated by many existing GPT models. Using the case of the diffusion of electrical power in the early twentieth century this paper shows that there was no generalized productivity boost from electrical power diffusion as postulated by many existing GPT models. The productivity gains from this GPT varied widely across economies and industries, suggesting that the power of GPTs to predict aggregate or sectoral growth is limited.
\end{abstract}

KEY WORDS: General Purpose Technologies, Economic Growth, Economic History, Productivity, Long Swings

JEL CLASSIFICATION: N11, N12, N13, N14, N60, O40 


\section{INTRODUCTION}

This paper challenges the usefulness of General Purpose Technology (GPT) theory as a way of conceptualising the relationship between technological advances and long-term historical economic growth. We do this by concentrating on GPT theory's main and most intuitive claim: that the introduction of a GPT must have long-term positive repercussions on growth through a non-ephemeral shift in productivity.

To make our case we look at electricity diffusion in the early twentieth century. Electricity is one of the very rare examples of a technology that is unanimously seen in the literature as an historical example of a GPT. The consensus is that in the early twentieth century electricity diffusion improved aggregate productivity mainly by increasing labour productivity in the manufacturing sector. We therefore investigate the link between electricity diffusion and labour productivity in this sector where the effects of the new GPT should be more obvious and prominent. We start by looking at the quantitative record of the relationship between electricity diffusion and productivity in the long term in a comparative perspective by employing time-series quantitative methods to investigate the historical experience of a number of industrial countries beyond the United States. We find that the result previously observed for the US of a strong relationship between electricity diffusion and long-term productivity increases cannot be readily extended to other countries. The claim to generality of the GPT theory seems substantially weakened by the fact that there are examples of countries in which electricity diffusion does not engender a positive shift in long term productivity.

Moreover, we complement this finding by investigating the micro-level mechanism that supposedly underpins the relationship between electricity diffusion and productivity. This mechanism is that the diffusion of electricity had considerable effects on aggregate productivity because it brought about substantial productivity increases in a countless variety 
of industrial processes and sectors (the 'general' part of GPT). To look at the relationship between electricity diffusion and productivity shifts at the micro-level we use the example provided by the UK manufacturing sector in the early 1930s. The UK Census of Production for 1935 is one of the few historical sources outside the US that provide extensive disaggregated data on output, labour input and electricity consumption by industry. On the basis of this data we observe that the correlation between electricity diffusion and labour productivity is at best moderate and on many counts weak.

There are five steps to our analysis. In section 1 we review the literature. In section 2 we present our data providing quantitative evidence on electricity usage in the manufacturing sector on a per worker basis for five of the major industrial countries before WWII. In section 3 we use this macro data to show that, at the aggregate level, the national electricity diffusion paths were not necessarily associated with a productivity bonus in the manufacturing sector. This result challenges the heuristic power of the key empirical macroeconomic hypotheses of the GPT literature. In section 4 we use detailed disaggregated information on electricity consumption per worker and output growth contained in the UK Census of Production for 108 manufacturing industries for the years 1930 and 1935 to assess the nature, spread, and effects of the electricity diffusion process at the industry level. Again we fail to find unambiguous evidence of a clear relationship between electricity diffusion and surges in productivity. In section 5 we conclude by observing that the theory in itself is problematic as it gives undue emphasis to one dimension of the effects of technological innovation over productivity (the width of the diffusion process) while underplaying two other dimensions that are in principle equally important (the depth of the potential productivity benefits and the rapidity of the diffusion of the new technology). As such the theory provides an inaccurate description of historical economic growth. 


\section{GPT THEORY AND ELECTRICITY: A SURVEY}

That technological change is an important determinant of modern economic growth is an idea that most economists would agree upon. However, the details of this relationship are less clear. In the last two decades a new way to conceptualise the relationship between technology and growth has emerged: the idea of General Purpose Technologies. GPTs are seen as infrequent but pervasive exogenous technological shocks able to generate low frequency (long-term) positive effects on economic growth by transforming the productivity potential of economies (Jovanovic and Rousseau, 2005; Aghion and Howitt, 2009).

To date much of the work on GPTs has been theoretical in nature, informing us of possible outcomes for economic growth but offering limited insights on actual historical economic growth. Working with fairly simple prototype models of GPTs a number of macroeconomic growth hypotheses have been accepted in the literature; for example, much of the early literature (Hornstein and Krusell 1996, Greenwood and Yorokoglu 1997), argues that the diffusion of a new GPT is correlated with a productivity slowdown in the early phase of the diffusion process, and after some time this is followed by productivity acceleration. As the title of a 1998 article by Helpman and Trajtenberg put it there would be "a time to sow and a time to reap". ${ }^{1}$ Indeed it is these growth effects that make GPTs inherently different from other technological changes. As Helpman (2004, p. 51) puts it:

Growth that is driven by general purpose technologies is different from growth driven by incremental innovation. Unlike incremental innovation, GPTs can trigger an uneven growth trajectory, which starts with a prolonged slowdown followed by a fast acceleration.

This idea can also be found in David (1991), in Bresnahan and Trajtenberg (1995), in Helpman and Trajtenberg (1998a and 1998b), in Aghion and Hewitt (1998) ${ }^{2}$ and has been

\footnotetext{
1 This hypothesis follows David (1990).

${ }^{2}$ A similar argument is developed earlier by Phelps-Brown and Handfield-Jones (1952) as an application to the late nineteenth century "climacteric" in Britain's economic growth.
} 
specified as a stylized fact of economic growth in the survey of GPTs by Jovanovic and Rousseau (2005, p. 1187) who state:

But overall the evidence clearly supports the view that technological progress is uneven, that it does entail the episodic arrival of GPTs, and that these GPTs bring on turbulence and lower growth early on and higher growth and prosperity later. The bottom line is that with a wider body of data and fifteen more years of it than David (1991) had at his disposal, we confirm his hypothesis that Electrification and IT adoption are manifestations of the same force at work, namely the introduction of a GPT.

And yet GPT models are not univocal in their predictions of the effects of GPTs on productivity. For example the prediction of a productivity slowdown in the early stages of the arrival of a new GPT is not universally accepted, and part of the theoretical literature on GPTs casts doubts as to whether a slowdown is a necessary feature of describing the effects of a new GPT (Lipsey et al., 2005). The only feature that seems common to all GPT models (and has the most intuitive appeal) is that the introduction of a new GPT should eventually determine a productivity surge. Therefore, here we use the available data to evaluate the evidence only on the central claim of the GPT theory, that of a productivity bonus.

GPT models are, at present, simple thought experiments and have serious limitations when used to describe and explain historical economic growth. Lipsey et al. (2005, p. 384) review the literature as it developed since the early 1990s and argue that all models to date share the common problem that they deal with a complex historical economic system inappropriately, seeing shifts in the rate of economic growth as the outcome of a single GPT. In reality, at any point in time, change in the rate of economic growth will be an outcome of the stock of GPTs at different stages of their life cycle, and as such, the link between a particular GPT and historical economic growth is not uniquely determined. So while episodic effects on economic growth are a reasonable research hypothesis, the expectation that they would generate long-term growth regularities or quasi-cyclical patterns in the shape of a productivity slowdown followed by a productivity surge is far more questionable. 
In the last few years the GPT approach has come under growing attack. Joel Mokyr suggested that it can hardly be described as a theory and that its academic currency is on the wane (Mokyr, 2006). Alexander Field (2011) convincingly suggests that GPT theory has little heuristic power. Moreover he shows that the criteria commonly used by the literature to identify GPTs and to separate them from the rest of technical progress (what Helpman describes as incremental innovation) are at best subjective. But they are also flawed in the sense of being too restrictive and to exclude technological transformations likely to produce significant growth effects. Indeed the impossibility of effectively using the proposed criteria for GPT selection has led to the compilation of vastly subjective and heterogeneous lists of historical examples of GPTs. The heterogeneity of choice is such that only three GPTs appear in all the eleven compilations surveyed by Field. They are what Field calls the Big Three namely: (1) IT or ICT (or more specifically semiconductors, or computer, or Internet); (2) electricity; and (3) steam. These are indeed the three GPTs mentioned in the original article by David (1990) from which much of the GPT literature originates.

Field observes that steam has already been dealt a serious blow in its status as a GPT by Crafts and Mills (2004). Moreover, we note that it is very difficult to describe steam as a GPT as its application was restricted to an exceedingly small number of uses for the first half century after Newcomen’s Dudley Castle Machine of 1712. Even after Watt invented the separate condenser, steam engine take-up remained for many decades slow and limited to a handful of uses (mostly mining). Similarly, the development of high-pressure steam engines in the first two decades of the nineteenth century did not expand steam use much beyond the realm of mining. It is only with the further advances in high-pressure technology and with the arrival of compounding in the 1840s and 50s, that steam can start to lay claims of generality in its use at least when it comes to textile production, metallurgy, land and, later, sea transport. Yet, even in 1870 two thirds of steam power was concentrated in coal-mining, 
cotton textiles, and metal manufactures (Crafts and Mills, 2004). In other words it took more than a century and a half for steam to become a GPT. The development of steam was so slow, its diffusion process so gradual, as to prevent any of the sudden accelerations and decelerations in growth and productivity that theory associates with GPTs.

This leaves GPT literature with only two agreed examples: ICT; and its historical antecedent: electricity. We concentrate on the latter. In particular we look at the diffusion of electricity in the manufacturing sector before World War II. The focus on the manufacturing sector is the result of evidence indicating that the acceleration in US labour productivity growth during the 1920s originated almost entirely in the manufacturing sector (David and Wright, 2003; Field, 2011). This surge in labour productivity in the manufacturing sector was common to all manufacturing industries and accounted for a substantial proportion of the increase in TFP observed in the first part of the interwar years. If there is a productive sector where the effects of electricity as a GPT on productivity should be magnified and easily detectable it is likely to be manufacturing.

To evaluate the hypothesis of a link between GPT and productivity growth we have built a new comparative data set of electricity diffusion in the manufacturing sector for the major industrial economies of the twentieth century - covering the US, the UK, France, Germany and Japan ${ }^{3}$. The selection of countries allows us to compare the experience of the US, as the technological leader, with the technologically 'relatively backward' economies of the early twentieth century.

David and Wright (2003) focus on the considerable acceleration of productivity growth in the US in the 1920s and associate this with a substantial increase in labour productivity and a concurrent fall in capital intensity in the US manufacturing sector. They see the upsurge in labour productivity as a direct result of the diffusion of electricity-based

\footnotetext{
${ }^{3}$ The data is described in full in a Data Appendix available online on the EREH's site.
} 
GPTs in production, and of the supply shock to the labour market caused by increasing restrictions on mass-immigration. Although David and Wright also consider the experience of Britain and Japan, they rely on a descriptive analysis of the diffusion of electricity in the manufacturing sectors for these economies ${ }^{4}$. We further this work by building a comparative data set of electricity consumption per worker in the manufacturing sector for the major industrial countries before WWII as a way of quantifying the hypothesis of a productivity surge made within the GPT theoretical framework.

To date the literature on the effect of electricity diffusion on aggregate output has mostly been based on a descriptive evaluation of historical productivity data. For example, David and Wright (2003) use Kendrick's productivity data to show the existence of a high growth phase in the 1920s. Jovanovic and Rousseau (2005) use ocular inspection of a Hodrick-Prescott trend of growth rates in output per man-hour to justify evidence of a productivity bonus. Our aim is to use time series techniques to describe the trend movements of economic growth as a way of avoiding selection bias.

\footnotetext{
${ }^{4}$ This leads David and Wright (2003, pp. 147-55) to argue that the use of electricity in manufacturing in Japan and Britain matched that of the US by the 1930s with similar productivity surges, suggesting that follower countries can accelerate the benefits of using the new technology. We show below that the quantitative evidence suggests that the US maintained its leadership position throughout the interwar period, even though Britain and Japan were diffusing the use of electricity in manufacturing rapidly in the interwar period.
} 


\section{MEASURING THE ADOPTION OF ELECTRICITY IN THE MANUFACTURING SECTOR.}

The traditional indicator of the extent of electrification of production has been the capacity of primary electric motors. These are motors driven by electricity purchased from utilities and, therefore, not produced within the plant. An indicator of the extent of electrification of production in the manufacturing sector that is directly linked to labour productivity is the capacity (in $H P$ ) of primary electric motors per employee. Data on primary electric capacity is relatively easy to find, but it should be noted that such an indicator has serious drawbacks as a means of thinking about the effects of the electrification of production methods. Electric motors were not necessarily employed at the same rate across countries because of differences at the national level in the number and length of shifts over which industrial machinery is operated in one day. Moreover, the existence of secondary electric motors (those run on electricity produced within the industrial establishment), introduces a further element of confusion in the comparative exercise. A better and more direct way to assess the comparative contribution of the electrification of manufacturing processes to the growth of productivity is to use measures of electricity consumption per worker in the manufacturing sector. The total electricity consumed by the US manufacturing sector in $G W h$ is available in the Department of Commerce (1975, series D130). From this and from the data on employment in the manufacturing sector (Kendrick, 1961) we have obtained the observations on the electricity consumed per employee in the US manufacturing sector that appear in Figure 1.

In order to be able to make international comparisons with the experience of the US we have constructed a similar data set for the total electricity consumed per employee in the UK, French, German and Japanese manufacturing sectors. A comparison of the consumption of electricity per employee in the manufacturing sector in these five countries is presented in Figure 1. This confirms that the adoption of electrical technologies in production was 
markedly delayed in the European core countries and Japan as compared to the US. The electricity consumed by each employee in the US manufacturing sector remained three times as high as that consumed by his/her European counterpart for much of the period, and fell below this threshold only in the last part of the 1930s Great Depression.

Two key conclusions emerge from this new comparative data set. First, it is clear that the use of electricity in the manufacturing sector was far more extensive in the US than in the other major economies of the inter-war period. The lag between the leader and followers suggests that by the early 1920s the other economies had a comparable usage of electricity in manufacturing to that of the US around 1907. By the mid-1930s the follower countries had a comparable usage to the US in 1920. This result differs from the description of the diffusion of electricity in follower countries during the interwar period by David and Wright (2003) who claim that “...by the end of the 1930s the extent of diffusion of electric power in British manufacturing as a whole essentially matched that in the US.” 5

The quantitative comparative evidence suggests that the US managed to use more electricity per worker earlier than other countries and was able to sustain this lead even when other countries were making significant strides in diffusion in the inter-war period. The reason for the US lead in the use of electricity per worker is related to the rich resource endowment of the US, resulting in the relative cheapness of electricity. This in turn was due to the relative cheapness of thermal generation in the US, owing to the low price of the natural resources (oil and coal) employed. This hypothesis can be evaluated using census data for Britain and the US. In 1935 the British manufacturing sector was reported to have bought $7,100 \mathrm{GWh}$ of electric energy at a cost of $£ 23,570,000$. This meant that the average cost of a

\footnotetext{
${ }^{5}$ David and Wright, 2003, pp. 149-50. As pointed out in Section 4 below, one way to reconcile this view with the evidence is that the use of electricity in the UK and Japan suggests a widening of use but the intensity and extent of use (measured as electricity per worker) was relatively low compared to the USA.
} 
KWh for the British manufacturer was $£ 0.00332$ or $0.80 d$ of the time. ${ }^{6}$ At the prevailing exchange rate of \$ 4.971 per pound (Mitchell 1988, p. 703) in 1935 the price of a KWh bought by the average British manufacturer was equal to $\$ 0.0165$. As a term of comparison we observe that in 1929 and 1937 the average price paid by US manufacturers to acquire a $K W h$ was $\$ 0.0127$, and $\$ 0.0102$ respectively. ${ }^{7}$ This suggests that the price of electricity paid by British manufacturers in 1935 was ca. 50 per cent higher than that paid by their US counterparts. Given the strict correlation between the cost of electricity and the cost of its direct substitutes (coal, oil, etc.), this price differential indicates that sources of power in general were considerably cheaper in the US than in the UK. In turn, this should be a strong indication of the energy intensive nature of production in the US, provided that one takes the not entirely unreasonable view that other production inputs such as capital and labour were not substantially cheaper in the US than in the UK (Broadberry, 1997, p. 101). Indeed, there is strong evidence to suggest that the cost of labour relative to the cost of electric energy in manufacturing was at least twice as high in the US than in the UK, France, Germany and Japan for the duration of the second quarter of the twentieth century (Broadberry 1997, table 7.5, p. 101 and Melman 1956, p. 206 and 213). We can only agree with Broadberry’s remarks on the likely continuation of the effect of energy endowments on comparative labour productivity in the rest of the century (Broadberry 1997, p. 102). ${ }^{8}$

\footnotetext{
${ }^{6}$ Our calculation is made on the basis of the individual industry cost returns of the 1935 UK census of production. The original figures refer to electricity purchased and used, including electricity generated in other works under the same ownership.

${ }^{7}$ Our calculations are based on data from the 1939 US census of manufactures. Note that the data on the US KWh cost in manufacturing given by Broadberry 1997 in table 7.5 p. 101 is mistakenly expressed in pence, while it should be expressed in US cents (see Melman 1956, p. 206). Also note that the Melman's calculations based on the electricity price paid by large manufacturers are very close to our calculations based on the more comprehensive census returns in the US case, and are substantially lower than for the UK ( $0.69 d$ as opposed to our $0.80 d$ ).

${ }^{8}$ Abramovitz and David (2000, pp. 50-53) stress the fundamental importance of natural resource abundance in shaping the form, rate, and underlying technologies of US growth up to the first quarter of the twentieth century. They also maintain that natural resource abundance continued to play an important role in US growth in the rest of the century. In a similar fashion Wright (1990, p. 651) notes that “ . .. the single most robust characteristic of American manufacturing exports was intensity in nonreproducible natural resources. In fact, their relative resource intensity was increasing over the half-century prior to the Great Depression.” Resource abundance
} 
The second key feature of the new data set is that the major European economies shared a common experience in the adoption of electricity in the manufacturing sector, despite their differing stages of development and per capita income (Japan shared a similar trend from a lower level of electricity per worker). This common path of electricity adoption by the European countries provides an opportunity to evaluate whether any productivity effects also follow common movements.

\section{A PRODUCTIVITY-BONUS FROM ELECTRICITY USAGE? TIME SERIES EVIDENCE.}

David and Wright (2003) see the upsurge in labour productivity growth in the USA during the 1920s as a direct lagged result of the diffusion of electricity-based General Purpose Technology in manufacturing production. This explanation for US economic growth in the 1920s is seen as a first approximation as they also stress the importance of other variables. To illustrate the extent of trend acceleration they use Kendrick's manufacturing sector productivity data to show the existence of a low growth phase during 1889-1913, compared to the 1920s. For most of the 1920s the rate of growth of labour productivity was clearly high, averaging five per cent per annum during 1920-29. table 1 calculates the geometric growth rates for a number of long period comparisons. US labour productivity growth before 1913 displays as a series of long swings (Abramovitz 1961; 1968), representing periods of accelerated and retarded economic growth. The acceleration of growth rates observed during $1900-1913$ relative to $1889-1900$ is mainly cyclical in nature, comparable in magnitude to the acceleration of the 1880 s.

characterises US industry as a whole in the last two centuries, and it is a necessary condition for many of the distinctively American industrial developments in this period (ibid. p. 653, and p. 661). 
Table 1: Labour productivity growth in US manufacturing (per cent growth per annum)

\begin{tabular}{lc} 
& GROWTH RATE \\
\hline \hline $1869-1879$ & 0.72 \\
$1879-1889^{9}$ & 2.20 \\
$1889-1900$ & 0.85 \\
$1900-1913$ & 1.89 \\
\hline
\end{tabular}

Clearly the five per cent growth rate observed in the 1920s is historically unprecedented even if compared only to high growth episodes in the past. This interpretation of US economic growth is supported by other research. Harrison and Weder (2009) stress the very high total factor productivity growth of the 1920s as evidence of a supply-side technology based explanation of high US economic growth. Although Field (2011) raises some doubts about the idea of GPT he agrees with the productivity bonus effects of electricity use in manufacturing during the 1920s.

To assess the magnitude of the productivity bonus we focus on describing the trend movements in labour productivity growth using a number of time-series techniques. Economic historians have described the cyclical path of the US economy before World War II as displaying a number of cycles of differing durations. The average period of the long swing fluctuations was around the 20 -year frequency ${ }^{10}$. To analyse the extent of trend acceleration we use two models of time series decomposition that are able to deal with this

\footnotetext{
${ }^{9}$ The pre-1889 data are based on the benchmark years of 1869, 1879 and 1889.

10 Jones and Olken (2005) have described this feature of modern economic growth as "Start-Stop Growth", entailing large swings of growth within twenty-year intervals. Comin and Gertler (2006) have emphasised the importance of "medium-term business cycles". Although both these studies focus on the US experience after World War II, the pre WWII period displayed similar growth features.
} 
cyclical structure. ${ }^{11}$ First, we use the unobserved components time series model of Harvey (1989) to describe the trend in labour productivity once we model a short business cycle and a long-swing in the data. Although such a time-series structural model has the limitation of imposing a specific structure upon the data, it has the advantage of nesting two extreme specifications for the trend, the deterministic or trend-stationary model and the stochastic trend or 'difference stationary' model. We also use the wavelet methodology to decompose labour productivity data into “approximations” and “details”: approximations capture the high-scale, low-frequency (trend) components of the data; and the details are the low-scale (cyclical) components. The major advantage of the wavelet method is that the semi-parametric nature of the decomposition is able to capture the irregular nature of the period and amplitude of economic cycles and captures cyclical processes of different durations. The trend in the US labour productivity that results from these time-series models is depicted in Figure 2. Both decomposition methods yield similar trend lines; the proportional differences between the two trend lines mainly range around two per cent.

Another filter that is widely used in business cycle discussions is the HodrickPrescott filter. We use the trend estimate obtained with this filter as a robustness check on the trend descriptions that arise from our other two models (Unobserved Components, and Wavelet Methodology). Clearly, as is well known, the H-P filter retains much of the low frequency cyclical movements in the data within the trend component which explains the more cyclical-looking trend line. For the wavelet method and the Kalman filter structural model these low frequency movements have been explicitly decomposed in the trend-cycle decomposition. Hence, although the different filters display differences regarding the cyclical movements of the economy they all agree that the trend component of US labour productivity displays non-linear process with some trend-acceleration observed in the interwar period

\footnotetext{
${ }^{11}$ Both methods are outlined in detail in the Technical Appendix available online on the EREH's site.
} 
relative to the past. The movements of labour productivity in the manufacturing sector suggests that a productivity bonus is observed in the interwar period but the trend improvement is relatively mild compared to the large swings of growth observed in the 1920s and 1930s. Hence, there is evidence of a productivity bonus in two forms: first, there is some trend acceleration in the trend component of productivity growth ${ }^{12}$; second, the much higher cyclical volatility of the interwar data generated a high amplitude long swing in productivity during the 1920s and 1930s.

Figure 3 plots British manufacturing sector labour productivity together with the trend estimates from the structural time series model, the wavelet model and H-P filter. All three estimates of the trend performance of productivity in the manufacturing sector are agreed on the broad picture; the trend displays segmentation in the interwar period with a period of trend acceleration in productivity growth. ${ }^{13}$ The major gain in manufacturing sector productivity growth begins in the 1920s and maintains momentum into the 1930s. Since the UK manufacturing sector productivity bonus is observed over the inter-war period as a whole this raises doubts about the ability of GPT theory to rationalise these trends as the UK began the 1920s well below the US in its level of electricity per worker. In light of the evidence for the diffusion of electricity usage in British manufacturing, it seems reasonable to conclude that the British manufacturing sector was also able to enjoy significant productivity gains from the adoption of electricity in manufacturing during the interwar period but that these effects on productivity came to fruition much more rapidly than implied by GPT theory.

This description of the trend performance of British industry differs from some existing analyses of inter-war growth trends. Greasley and Oxley (1996) describe a significant segmentation of the trend path of industrial output that was negative following the

\footnotetext{
${ }^{12}$ As argued by Field (2011) it is important to consider the trend estimate for the USA up to the period 1941-2 if we are to get a sense of the longer term trend movements of the USA. Hence Figure 2 for the USA is displayed over a slightly longer period than the figures for the other countries which end in the 1930s.

${ }^{13}$ This feature of the growth process is observed with simple descriptive statistics- over the period 1920-38 the mean growth rate of labour productivity doubled relative to the pre-1913 period.
} 
adverse shocks observed in 1920-1. The results presented above for manufacturing sector productivity suggest the opposite view is consistent with the evidence ${ }^{14}$, with productivity growth making significant strides in the interwar period. Crafts (2011) has also postulated a pessimistic view on productivity growth, particularly for the 1930s. We find that the trend improvement in the manufacturing/industrial sector is a feature of the inter-war period as a whole. Crafts' thesis is that the supply-side policy framework of the 1930s was not conducive to rapid productivity growth. If this hypothesis is correct, then other variables must have had very large effects to compensate for this given the trend-acceleration path of industry-sector productivity.

An index for Japanese manufacturing sector labour productivity has been constructed on the basis of the employment data contained in Umemura et al. (1988), and of the output of the Japanese manufacturing industry over the period 1896-1940 taken from the Japanese historical national accounts (LTES) ${ }^{15}$. Figure 4 displays Japan's manufacturing sector labour productivity: the growth rate averaged $1.72 \%$ per annum over the period $1896-1940$ but labour productivity fluctuated significantly about trend. The three trend estimates for Japan are also presented in Figure 4. The existence of large swings in productivity growth in Japan makes the identification of trend breaks more difficult. Nevertheless, all estimates capture some acceleration in the interwar period, although the specific timing differs.

In the case of Germany the limited availability of annual data means that we cannot employ formal methods to derive an estimate of labour productivity trends. Instead we rely on descriptive statistics to build a picture from the available data. Figure 5 plots labour

\footnotetext{
${ }^{14}$ The path of manufacturing sector output and industrial production in general move one for one, suggesting that the differences between our results and the description of Greasley and Oxley is not due to compositional effects.

${ }^{15}$ The data overlap in 1919 and 1920 allowing us to scale the pre-1919 series to be comparable to the interwar series. The employment data were estimated on the basis of annual surveys of establishment with more than nine employees before 1919, of establishments with more than four employees for the period 1919 - 1937, and for all establishments from 1938 onwards. The extrapolation for the smaller establishments before 1938 and the coverage of the State-owned establishments were originally obtained using industrial census information and more comprehensive local surveys when available.
} 
productivity in the German manufacturing sector on a logarithmic scale using annual data over the period 1885-1938 (there are gaps in the data series over the trans-war period 191424). Some benchmarked data for the period 1875-1885 also exist and is included for analysis. During the pre-1913 period labour productivity growth averaged $2.1 \%$ per annum over the period 1886-1913. Although the manufacturing sector's labour productivity growth rate over the inter-war period was higher - the growth rate of 1925-38 averaged $2.81 \%$ per annum, given the greater variance of interwar growth rates this difference in growth was not large enough to stand out as statistically significant. Hence, the productivity bonus observed in the USA, UK and Japan is absent in the case of Germany.

In the case of France the availability of data to discuss pre-1914 trends is limited. Labour input data is available only for a few benchmarks observations between 1872 and 1911, which limits us to drawing inferences on the underlying trend. ${ }^{16}$ The trend rate of growth of labour productivity growth in industry was below one per cent per annum during the period 1872-1911. For the interwar period we were able to build an index of manufacturing sector labour productivity for the period $1921-38 .{ }^{17}$ This is presented in Figure 6. It is clear that during the 1920s labour productivity growth in French manufacturing displays high growth rates (representing a doubling of the pre-1911 trend growth rate). However, with the onset of depression in the 1930s, France enters a phase of stagnant productivity growth which extends throughout the lost decade of the 1930s.

Summarising, whilst a productivity bonus is observed in the case of the USA, for the four remaining countries here considered things seem more complex. Although the UK, Japan, Germany and France share a common path of electricity diffusion in the manufacturing sector, their productivity growth paths differ. For Britain and Japan we

\footnotetext{
${ }^{16}$ Benchmark observations exist for 1872, 1876, 1881, 1886, 1891, 1901, 1906 and 1911. We thank Jean-Pierre Dormois for providing us with the available French labour productivity data.

${ }^{17}$ Using the labour input calculations for the manufacturing sector and assuming that the trends in industrial production display significant co-movements with those for the manufacturing sector.
} 
observe trend acceleration spread out over the interwar period; for France productivity growth accelerates in the 1920s and stagnates in the 1930s; for Germany there is no trend acceleration. In light of these case studies the relationship between electricity as a GPT and productivity growth does not fit the stylized facts often found in the GPT literature, even as a first approximation to the growth process. This mixed comparative evidence should also act as a warning against seeing electricity as a GPT driving US economic growth over the

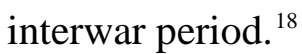

\section{ELECTRICITY DIFFUSION AND PRODUCTIVITY: DISAGGREGATED EVIDENCE FOR THE UK IN THE 1930s.}

Electrification is often seen as a GPT because its effects are seen to be pervasive in a multitude of industries. A GPT is seen as a yeast-like process that works itself across all industries. The disaggregated evidence for the USA reported in David and Wright (2003) suggests that this feature is important in understanding the productivity bonus of the 1920 s. The data contained in the $5^{\text {th }}$ Census of Production of the UK for the year 1935 allows us to observe electricity diffusion and productivity growth for another important case study. The Census describes 108 main sectors in manufacturing. ${ }^{19}$ In particular, tables I.A, and IX detail employment, total consumption of electricity and net output at current prices, by the factories with more than ten workers falling in each industrial category. Net output at current prices, has been traditionally transformed into net output at constant 1935 prices using price information from the censual data. Data availability for electricity consumption relates to

\footnotetext{
${ }^{18}$ Field (2011) notes that whilst electricity may have been important to the productivity acceleration in US manufacturing during the 1920s, a broader set of innovations determined productivity growth over the interwar period as a whole.

${ }_{19}$ The 1935 Census of Production covers also industries from the mining, and building industries and production under State and local authority ownership. Given that the focus of our investigation is the manufacturing industry we have dropped these additional sectors. Moreover, the Census gives separate readings for net output and employment for two sectors: "Iron and Steel (Blast furnaces)"; and "Iron and Steel (Smelting and Rolling)". Yet, it amalgamates them into a single sector called "Iron and Steel (Blast furnaces and Smelting and Rolling)" when it comes to electricity consumption. Therefore we conflated also the data on output and employment for these sector into figures for "Iron and Steel (Blast furnaces and Smelting and Rolling)".
} 
two observation points, one in 1930 and the other in 1935. The data confirms that electricity is quickly diffusing in this period. There are only 11 sectors out of 108 in which the increase in electricity consumption is lower than the growth in labour input. ${ }^{20}$ Similarly in more than two thirds of industries (79 out of 108) the increase in electricity consumption is above that in net output. The march of electrification in UK production seems nearly ubiquitous in the early 1930s. This confirms that electricity was diffusing extensively in British manufacturing during the 1930s and allows us to evaluate whether there is a marked positive correlation between growth in electricity consumption per worker and labour productivity as postulated by David and Wright for the American case (2003).

David and Wright's case that electricity diffusion would affect growth by markedly increasing labour productivity appears more tenuous for the British case. Columns 5 and 6 in table A.1 (in the electronic appendix to this paper) provide the rate of growth of labour productivity and of the consumption of electric energy per worker in the 108 sectors between 1930 and 1935. The correlation between these two is positive but weak $(r=0.22)^{21}$. These results suggest that the mechanism posited by David and Wright (2003), according to which the diffusion of electricity allowed for marked increases in labour productivity, was not at work in the British industry in the early 1930s.

If in this case electricity diffusion seems to be weakly correlated with increases in labour productivity it could be possible that it affected capital productivity and Total Factor Productivity. Unfortunately the 1935 UK Census of Production does not include independent observation on capital stocks. It is thus impossible to embark on a standard exercise in growth accounting. Nevertheless we can use that framework to investigate whether

\footnotetext{
${ }^{20}$ They are: (1) Packing; (2) Umbrella and Walking Stick; (3) Shipbuilding; (4) Railway Carriage and Wagon Building; (5) Carriage, Cart and Wagon; (6) Fish Curing; (7) Petroleum; (8) Manufactured Fuel; and (9) Musical Instruments; (10) Sports Requisites; and (11) Coopering.

${ }^{21}$ The correlation between labour productivity increase (column 5) and the growth in electricity consumption (column 4) is weaker $(r=0.15)$.
} 
electricity consumption affected a combination of capital input and TFP. Let us write a basic growth accounting equivalence in the following form:

$$
\frac{\Delta Y}{\mathrm{Y}}=\alpha \frac{\Delta K}{\mathrm{~K}}+\beta \frac{\Delta L}{\mathrm{~L}}+\gamma \frac{\Delta E}{\mathrm{E}}+T F P
$$

Where: $\frac{\Delta Y}{\mathrm{Y}}$ is output growth; $\frac{\Delta K}{\mathrm{~K}}$ is capital input growth; $\frac{\Delta L}{\mathrm{~L}}$ is labour input growth; $\frac{\Delta E}{\mathrm{E}}$ is increase in electricity consumption; TFP is the total factor productivity and $\alpha, \beta$, and $\gamma$ are non-negative constants with $\alpha+\beta+\gamma=1 . \quad \frac{\Delta K}{\mathrm{~K}}$ can be interpreted as investments not related to electricity. In line with conventional assumptions (see for example Harrison and Weder 2009, p. 366, or Field, 2011, p. 6) we set $\beta=0.7$. This parameter is also consistent with the estimates of factor shares from Matthews et al. (1982) for the interwar UK economy. There are obvious caveats that apply to any standard Cobb Douglas type growth accounting exercise. Nevertheless this framework can be helpful in allowing us to summarize the implications of the data. In our case we do not observe $\frac{\Delta K}{\mathrm{~K}}$ therefore we set:

$$
\alpha \frac{\Delta K}{\mathrm{~K}}+T F P=\psi
$$

A little manipulation yields for each of the 108 manufacturing sectors:

$$
\psi_{i}=\frac{\Delta Y_{\mathrm{i}}}{\mathrm{Y}_{\mathrm{i}}}-0.7 \frac{\Delta L_{\mathrm{i}}}{\mathrm{L}_{\mathrm{i}}}-\gamma \frac{\Delta E_{\mathrm{i}}}{\mathrm{E}_{\mathrm{i}}} \quad \text { where }(i=1, \ldots, 108) .
$$

This relationship allows us to investigate whether there is a strong positive correlation between large increases in the consumption of electricity and large residuals $\psi_{i}$. In order to calculate $\psi_{i}$ we need to set a value for $\gamma$. The objective is that of providing an upper-bound estimation for the residual (which is a sum of the capital input and of TFP). In order to do so we need to dampen the adverse effect that a fast growth in electricity consumption in sector $i$ would have on the residual in that sector by setting a low value for $\gamma$. We opt for a value of 0.1. Hence (3) becomes: 


$$
\psi_{i}=\frac{\Delta Y_{\mathrm{i}}}{\mathrm{Y}_{\mathrm{i}}}-0.7 \frac{\Delta L_{\mathrm{i}}}{\mathrm{L}_{\mathrm{i}}}-0.1 \frac{\Delta E_{\mathrm{i}}}{\mathrm{E}_{\mathrm{i}}}
$$

This allows us to calculate a residual $\psi_{i}$ for each sector (column 7 in table A.1 in the electronic appendix to this article). Again we find a mild positive correlation $(r=0.57)$ between growth in the consumption of electricity on one side and the combined effect of TFP and weighted investments on the other.

Clearly neither of these calculations provides a good approximation, let alone an actual measure, of the correlation between electricity diffusion and TFP. The problem arises from the high likelihood of a strong correlation between investment activity and electricity consumption. We know that in this period new production capital was very likely to embody new electricity-related technology. It is thus very likely that a considerable part of the observed correlation between electricity consumption and the residual $\psi_{i}$ is simply the result of the fact that increased consumption of electricity would require increased investments. To get a better sense of the relationship between electricity diffusion and TFP we must try to disentangle TFP from capital growth. A way to think around this problem is to assume that there would be no increase in electricity consumption without new investments in electricityembodying capital, and there would be no investments in new productive capital that is devoid of an electricity component. Under this common, but somewhat arbitrary assumption the growth in electricity consumption comes also to represent growth in investments $\left(\alpha_{\mathrm{i}}=0\right.$; $\beta_{\mathrm{i}}=0.7 ; \gamma_{\mathrm{i}}=0.3$ ) then we obtain the residual in column 9 of table A.1 in electronic appendix $^{22}$. This approximation yields a weaker correlation $(r=0.39)$ which is probably a closer indicator of the actual correlation between electricity consumption and TFP.

The conclusion of this exercise is that, at this level of disaggregation (108 industrial sectors), in the UK, during the early 1930s, the effect of electricity diffusion on labour productivity growth is weak. Although the effect of electricity diffusion on a combined

\footnotetext{
${ }^{22}$ Note that this is the implicit assumption commonly adopted in using HP increase as a proxy for investment in the 1930s, as in this period most of the increase in HP capacity is to do with new electrical installations.
} 
measure of Total Factor Productivity and growth of capital input is stronger than for labour productivity this is likely to be due in considerable measure to the strong correlation between investment activity and growth in electricity use. Without independent data on investment dynamics it is difficult to estimate the true TFP component of disaggregated growth. A rough approximation yields only a moderate correlation between electricity diffusion and sectoral TFP.

\section{CONCLUDING REMARKS}

Our examination of the relationship between electricity usage in manufacturing and productivity bonus in the manufacturing sector suggests that whilst a productivity bonus is observed in the case of the USA, for the four remaining countries here considered things seem more complex. Although the UK, Japan, Germany and France share a common path of electricity diffusion in the manufacturing sector, we observe heterogeneity in growth effects among them. For Britain, and to a lesser extent Japan, we observe trend acceleration spread out over the interwar period. As noted above, the similarity of trend acceleration in Britain and the USA in the 1920s is difficult to reconcile with a GPT perspective given the relative backwardness of the UK in the electricity diffusion process. Similarly, a GPT approach does not explain why, given a similar process of electricity diffusion the productivity path of the UK should differ so much from that of France where productivity growth accelerated only in 1920s but stagnated in the 1930s, and from that of Germany where there was no trend acceleration at all. In light of these case studies the relationship between electricity diffusion and productivity growth in manufacturing needs to be far more nuanced than is suggested by the stylized facts often found in the GPT literature. Clearly if GPT theory is meant as a first approximation to the growth process, there are potent second approximation effects capable 
of muddling and possibly obscuring any link between electricity usage and economic growth. Put it differently, the heterogeneity of growth movements in the major industrial countries of the twentieth century suggests that the role of technology diffusion can only be one of a number of important variables determining growth outcomes. The GPT literature has sought to find a link between technological innovation and growth by looking for evidence of trend acceleration in the time-scale of decades. However, it is clear that even within this timescale the determinants of productivity growth are not just technological. In our case the heterogeneity of the productivity paths of industrial countries may be explicable within a technological and a policy perspective. For example, France was able to gain a productivity bonus in the 1920s but was unable to do so in the 1930s under its membership of the Gold Bloc. Similarly although Germany was clearly diffusing electricity usage as fast as other countries the potential growth bonus was moderated by a sequence of adverse effects both in the 1920 s and the 1930 s.

Moreover, our investigation of the disaggregated effects of electricity diffusion among British industries in the early 1930s sounds further notes of caution over the heuristic power of GPT theory. We find that, although electricity was diffusing rapidly across British industries, the effect of electricity diffusion on labour productivity growth is weak.

Finally, our study of electricity as a GPT can be used in conjunction with other case studies to build a broader picture of GPTs and economic growth. Crafts and Mills (2004) examined the case of steam as a GPT in the nineteenth century and found no evidence to support the macroeconomic hypotheses of the GPT framework when trying to explain British nineteenth century economic growth. The failure of GPT theory to account for twentieth century growth suggests that caution is needed before we use GPT theory to explain historical economic growth. The bottom line is that the simplicity of GPT theory makes it an appealing theory of episodic growth but its simplicity is also its major weakness as a tool to investigate 
historical economic growth. Our analysis thus confirms the growing doubts about the usefulness of the concept of GPT. As Field observes, the GPT theory fails to unequivocally individuate more than three historical examples: steam, electricity, and ICT. Of these at least one (steam) is unlikely to have had much of a detectable effect on growth. The productivity bonuses associated with it seem to have taken such an inordinate amount of time to materialise (a century and a half after Newcomen's original invention) as to be quantitatively indistinguishable from the growth effects of a multitude of other technological changes of the nineteenth century. Our evidence on electricity supports the conclusions of Crafts and Mills (2004) that "the newfound enthusiasm for General Purpose Technology models of long run growth processes should not be taken too far”.

The historical case studies of steam and electricity raise the broader question of whether GPT theory can be a theory of macroeconomic growth - the inability of GPT theory to account for the historical record of growth raises strong doubts. What are we left with? With a theory that suggests that GPTs are pervasive technological changes (of which there are few agreed examples), that might or might not produce productivity accelerations. Being pervasive they are more likely than other technological changes to produce effects at the macro level but there are also many examples of less pervasive technological changes that are equally transformational. Presumably less pervasive technologies could have big effects on aggregate productivity if their effects on the productivity of the few sectors affected are of a truly substantial magnitude (depth of the effect), and/or if their introduction is comparatively fast and easy (the speed of the diffusion process). So we are back to the old truism that big technological changes are going to produce noticeable effects on growth and productivity trends. In summary, we might need to demote GPT theory to a specific case of a more general and mundane relationship between technology and long-term growth according to which a big (not necessarily a pervasive) technological change will have big effects. If it was 
a small technological change it would be likely to have small effects. This is hardly news and hardly a theory and more in the realm of what the French would describe as a lapalissade. ${ }^{23}$ Alternatively, GPT theory might be understood as suggesting that a GPT is, in fact, technological change that has all the characteristics of width (generality of diffusion), depth (substantial effects in terms of productivity) and speed (ease of diffusion). Being big, it would have big and detectable effects on long-term aggregate productivity. Unfortunately, should we accept this interpretation of GPT, we would find that there are no historical examples of such a transformative technology. The theory thus would be one that describes something that has never happened in the past. It is left to the reader to decide how useful an economic theory can be if it describes something that, albeit never experienced in the past, might, or might not, happen in the future.

\section{ACKNOWLEDGMENTS}

Research for this paper has been supported by a Research Grant from the ESRC (No. L138 25 1045). Jonathan Köhler, Adam Tooze, and Greg Clark provided useful comments to previous versions of this paper. We thank them for their help. We also thank the staff of the Bibliothèque nationale de France in Paris, of the Library of the London School of Economics, of the Marshall Library in Cambridge, of the Japanese Collection at the Aoi Pavillion of the Cambridge University Library, and of the Official Publications and Statistical Sources at the same library for their invaluable help in retrieving often obscure and rapidly decaying historical statistics and papers. The usual disclaimer applies.

\footnotetext{
${ }^{23}$ The term lapalissade comes from ironical verses stating the utterly obvious referring to the French General Jacques de la Palice or la Palisse (1470 - 1525).
} 


\section{BIBLIOGRAPHY}

ABRAMOVITZ, M. (1961). The Nature and Significance of Kuznets Cycles, Economic Development and Cultural Change, 9, Supplement, 225-48.

ABRAMOVITZ, M. (1968). The Passing of the Kuznets Cycle, Economica, 34, 349- 67.

ABRAMOVITZ, M., DAVID, P. A. (2000). American macroeconomic growth in the era of knowledge-based progress: the long-run perspective, in STANLEY L. ENGERMAN AND ROBERT E. GALLMAN (eds.), The Cambridge economic history of the United States. Volume III. The Twentieth Century, Cambridge: Cambridge University Press, 1-92.

AGHION, P., HOWITT, P. (1998). On the macroeconomic effects of major technological change, in HELPMAN, E. (ed.), General Purpose Technologies and Economic Growth, Cambridge MA: MIT Press, $121-144$.

AGHION, P., HOWITT, P. (2009). The Economics of Growth, Cambridge MA: MIT Press.

BOWLEY, A. S. (1944). Studies in the National Income: 1924 - 1938, Cambridge: Cambridge University Press.

BOWLEY, A. S., SCHWARTZ, G. L., RHODES, E. C. (1938). Output, employment and wages in the United Kingdom, 1924, 1930, 1935, Royal Economic Society Memorandum issued by arrangement with the London and Cambridge Economic Service, 75.

BRESNAHAN, T., TRAJTENBERG M. (1995). General Purpose Technologies: 'Engines of Growth'?, Journal of Econometrics, Special Issue 65, 83-108.

BROADBERRY, S. N. (1997). The productivity race. British manufacturing in international perspective, 1850 - 1990, Cambridge: Cambridge University Press.

COMIN, D., GERTLER, M. (2006). Medium-Term Business Cycles, American Economic Review, 96(3), 523 - 551.

CRAFTS, N. F. R. (2004). Steam as a General Purpose Technology: A Growth Accounting Perspective, Economic Journal, 114, 338-51.

CRAFTS, N.F.R. (2011). British relative economic decline revisited: The role of competition, Explorations in Economic History, 49(1), 17-29.

CRAFTS, N. F. R., MILLS, T. C. (2004). Was 19th century British growth steam-powered?: the climacteric revisited, Explorations in Economic History, 41(2), 156-71.

DAVID, P. A. (1990). The Dynamo and the Computer: An Historical Perspective on the Modern Productivity Paradox, American Economic Review, 80, 355-61.

DAVID, P. A. (1991). The Computer and the Dynamo The modern productivity paradox in a not-too-distant mirror, in OECD, Technology and Productivity: The Challenge for Economic Policy, Paris: OECD, 315-47.

DAVID, P. A., WRIGHT, G. (2003). General Purpose Technologies and Surges in Productivity: Historical Reflections on the Future of the ICT Revolution, in P.A. DAVID and M. THOMAS (eds.), Economic Future in Historical Perspective, Chapter 4, Oxford: Oxford University Press for the British Academy, 135-66. 
FIELD, A. J. (2003). The Most Technologically Progressive Decade of the Century, American Economic Review, 93(4), 1399-413.

FIELD, A. J. (2006). Technological Change and U.S. Productivity Growth in the Interwar Years, Journal of Economic History, 66(1), 203-36.

FIELD, A. J. (2011). A Great Leap Forward: 1930s Depression and U.S. Economic Growth, New Haven \& London: Yale University Press.

GOLDFARB, B. (2005). Diffusion of general purpose technologies: understanding patterns in the electrification of US Manufacturing 1880 - 1930, Industrial and Corporate Change, 14(5), 745-73.

GREENWOOD, J., YOROKOGLU, M. (1997). (1974), Carnegy Rochester Conference Series on Public Policy, 46, 49-95.

HARRISON, S., WEDER, M. (2009). Technological change and the roaring twenties: A neoclassical perspective, Journal of Macroeconomics, 31, 363-75.

HELPMAN, E. (2004). The mystery of economic growth, Cambridge MA: Harvard University Press.

HELPMAN, E., RANGEL, A. (1999). Adjusting to a new technology: experience and training, Journal of Economic Growth, 4, 359-83.

HELPMAN, E., TRAJTENBERG, M. (1998a). A Time to Sow and a Time to Reap: Growth Based on General Purpose Technologies, in HELPMAN, E. (ed.), General Purpose Technologies and Economic Growth, Cambridge MA: MIT Press, 55-83.

HELPMAN, E., TRAJTENBERG, M. (1998b). Diffusion of General Purpose Technologies, in HELPMAN, E. (ed.), General Purpose Technologies and Economic Growth, Cambridge MA: MIT Press, 85-119.

HORNSTEIN, A., KRUSELL, P. (1996). Can technology improvements cause productivity slowdowns?, NBER Macroeconomic Annual 1996, 11, 209-59.

HOWITT, P. (1998). Measurement, obsolescence, and General Purpose Technologies, in HELPMAN, E. (ed.), General Purpose Technologies and Economic Growth, Cambridge MA: MIT Press, 219-51.

JONES, B. F., OLKEN, B. A. (2005). The Anatomy of Start-Stop Growth, Review of Economics and Statistics, 90 (3), 582-587

JOVANOVIC, B., ROUSSEAU, P. (2005). General Purpose Technologies, in P. AGHION, and S. N. DURLAUF, (eds.), Handbook of Economic Growth, Volume 1B, Amsterdam and Oxford: Elsevier B.V., 1181-224.

KENDRICK, J. W. (1961). Productivity trends in the United States, Princeton: Princeton University Press.

LIPSEY, R. G., BEKAR, C. T., CARLAW, K. I., (1998). What requires explanation?, in E. HELPMAN (ed.), General Purpose Technologies and Economic Growth, Cambridge MA: MIT Press, 15-54.

LIPSEY, R. G., CARLAW, K. I., BEKAR, C. T. (2005). Economic Transformations: General Purpose Technologies and Long-term Economic Growth, Oxford: Oxford University Press.

MATTHEWS, R.C.O., FEINSTEIN, C. AND ODLING-SMEE, J. (1982). British Economic Growth, Oxford: Oxford University Press. 
MELMAN, S. (1956). Dynamic factors in industrial productivity, Oxford: Basil Blackwell.

MITCHELL, B. R. (1988). British historical statistics, Cambridge: Cambridge University Press.

MOKYR, J. (2006). Review of Richard G. Lipsey, Kenneth I. Carlaw and Clifford T. Bekar, Economic Transformations: General Purpose Technologies and Long-term Economic Growth, EH.Net Economic History Services, Aug 28 2006. URL: http://eh.net/bookreviews/library/1111.

OHKAWA, K., TAKAMATSU, N., YAMAMOTO, Y. (1974). National income, Volume 1 of M. OHKAWA, K., SHINOHARA, M., UNEMURA, M. (eds.), Estimates of longterm statistics of Japan since 1868, Tokyo: Toyo Keizai Shinposha.

ROSENBERG, N., TRAJTENBERG, M. (2004). A General-Purpose Technology at work: the Corliss Steam Engine in the late-nineteenth-century United States, Journal of Economic History, 64(1), 61-99.

UK BOARD OF TRADE; BUSINESS STATISTICS OFFICE, Census of Production: Final Report, (censuses 1924, 1930, 1948, 1951). London: HMSO.

UK MINISTRY OF POWER (1968). Statistical Digest 1967, London: HMSO.

UK MINISTRY OF POWER (1969). Digest of energy statistics 1968 and 1969, London: HMSO.

US DEPARTMENT OF COMMERCE, BUREAU OF THE CENSUS (1942). Sixteenth Census of the United States: 1940. Manufactures 1939. Volume I. Statistics by Subject, US GPO, table 4, p. 20; table 5, pp. 22-40; and table 1, p. 337.

US DEPARTMENT OF COMMERCE, BUREAU OF THE CENSUS (1933). Fifteenth Census of the United States. Manufactures 1929. Volume I. General Report. Statistics by Subject, US GPO, 1933, table 3, p. 16.

WRIGHT, G. (1990). The origins of American industrial success, 1879 - 1940, The American Economic Review, 80(4), 651-68. 
Figure 1. Consumption of electricity per employee in the manufacturing sector

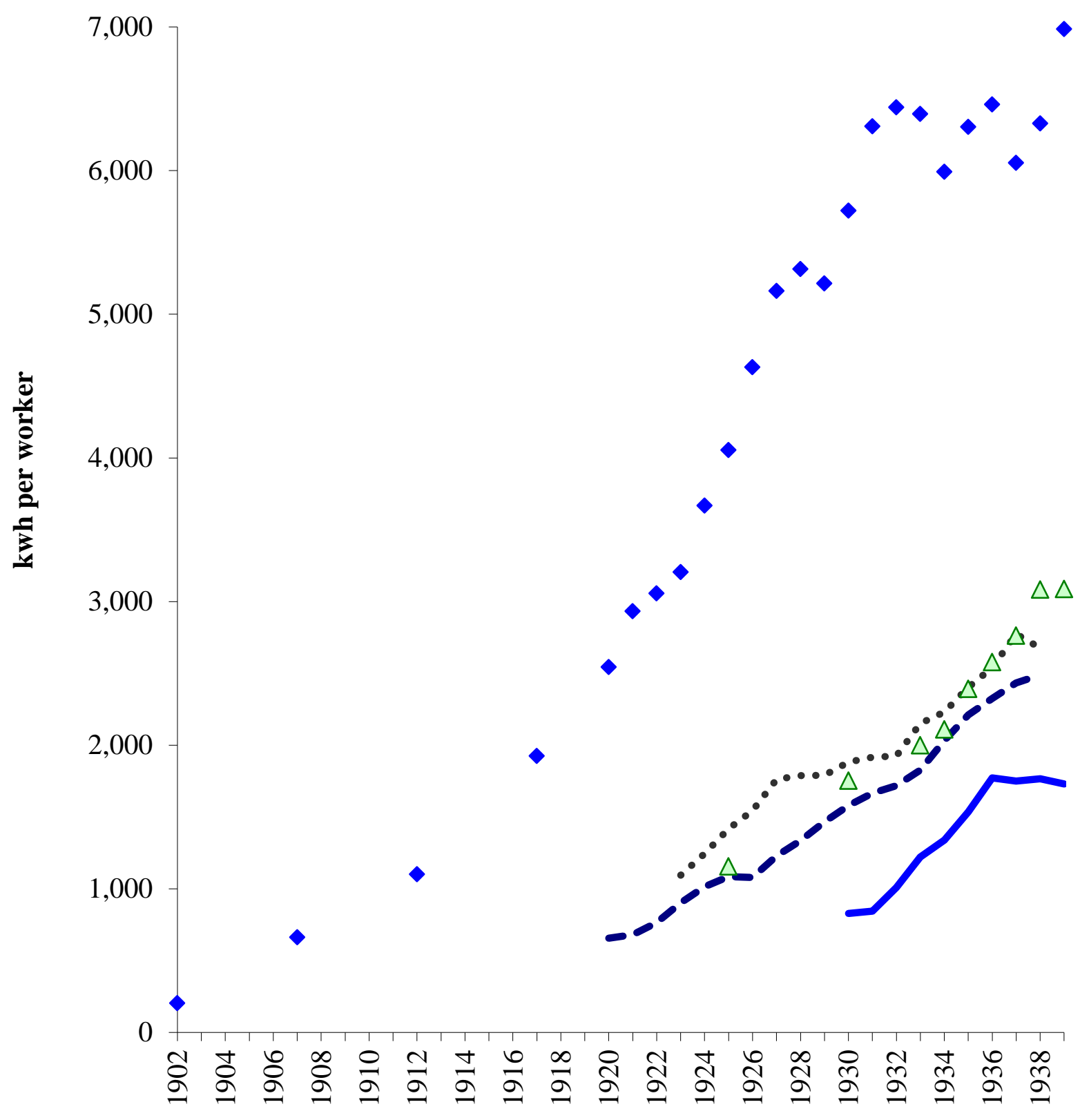

year

- US - - - Great Britain $\triangle$ Germany $\cdots$.... France —Japan 
Figure 2 : Trend Estimates in USA Manufacturing Sector Productivity (1889-1941)

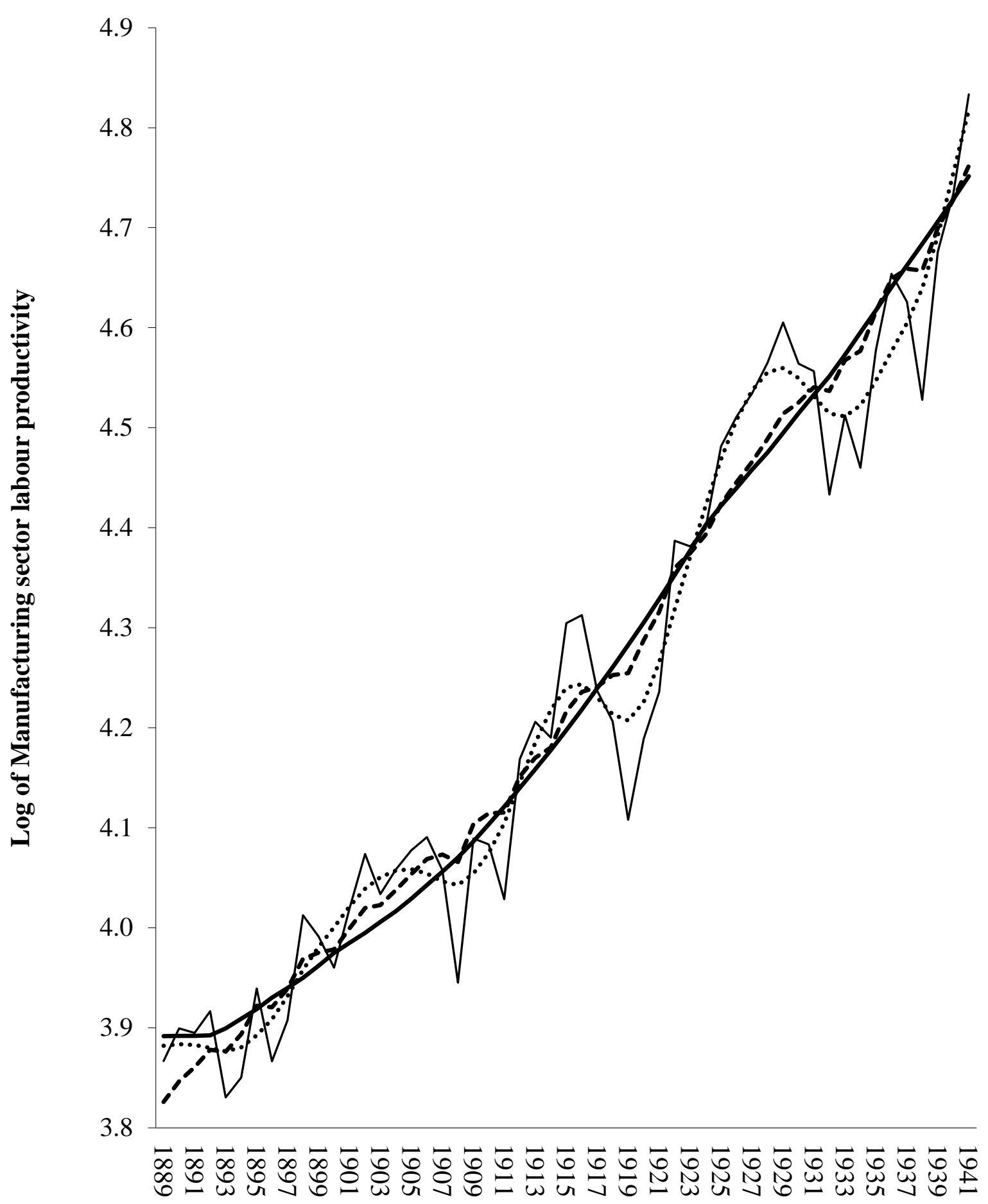

_ Labour productivity

----Structural Model Trend Estimate

Wavelet Trend Estimate

....... Hodrick-Prescott trend 
Figure 3 : Trend Estimates in UK Manufacturing Sector

Productivity (1869-1938)

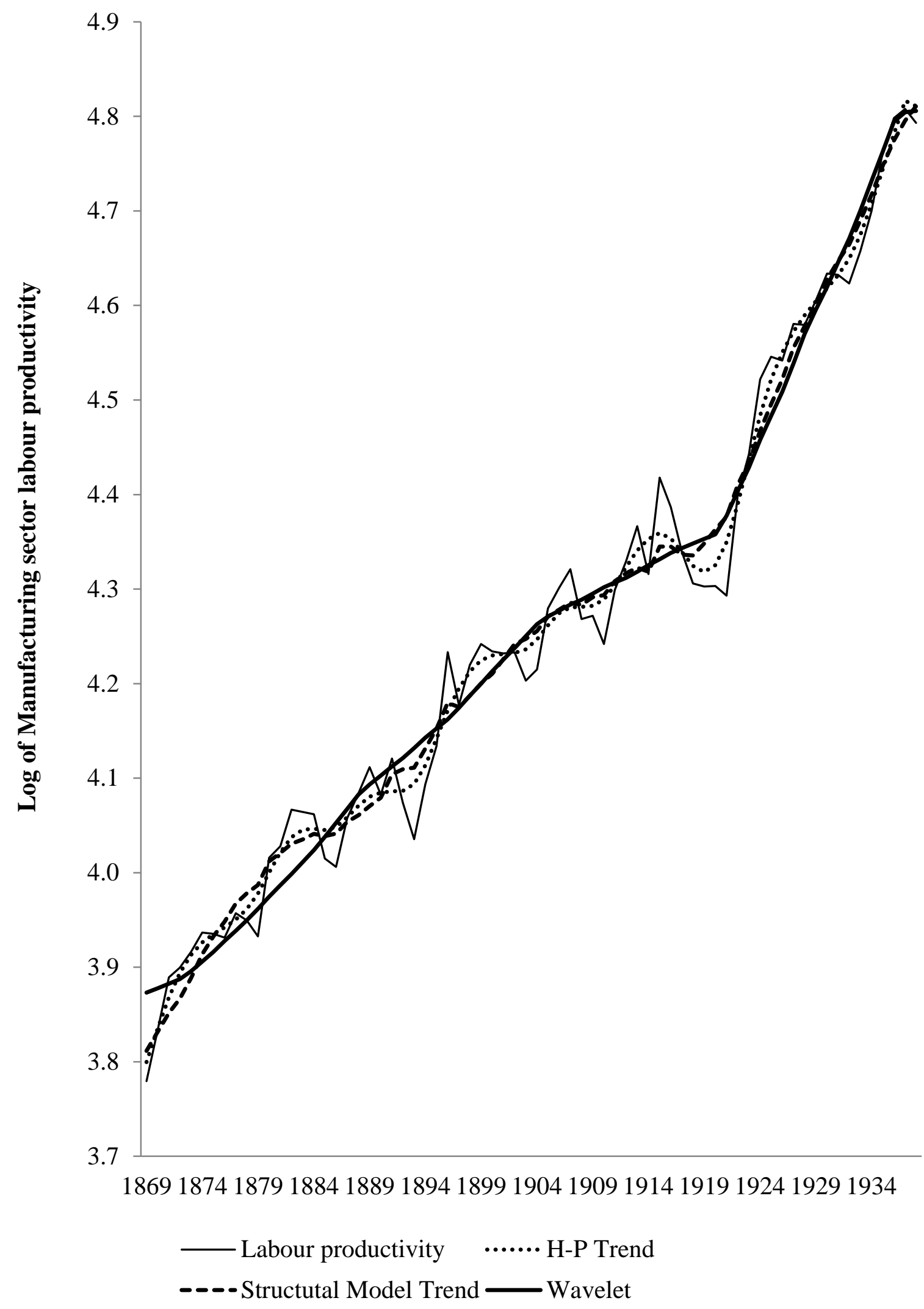


Figure 4 : Trend Estimates in Japan's Manufacturing

Sector Productivity: 1896-1938

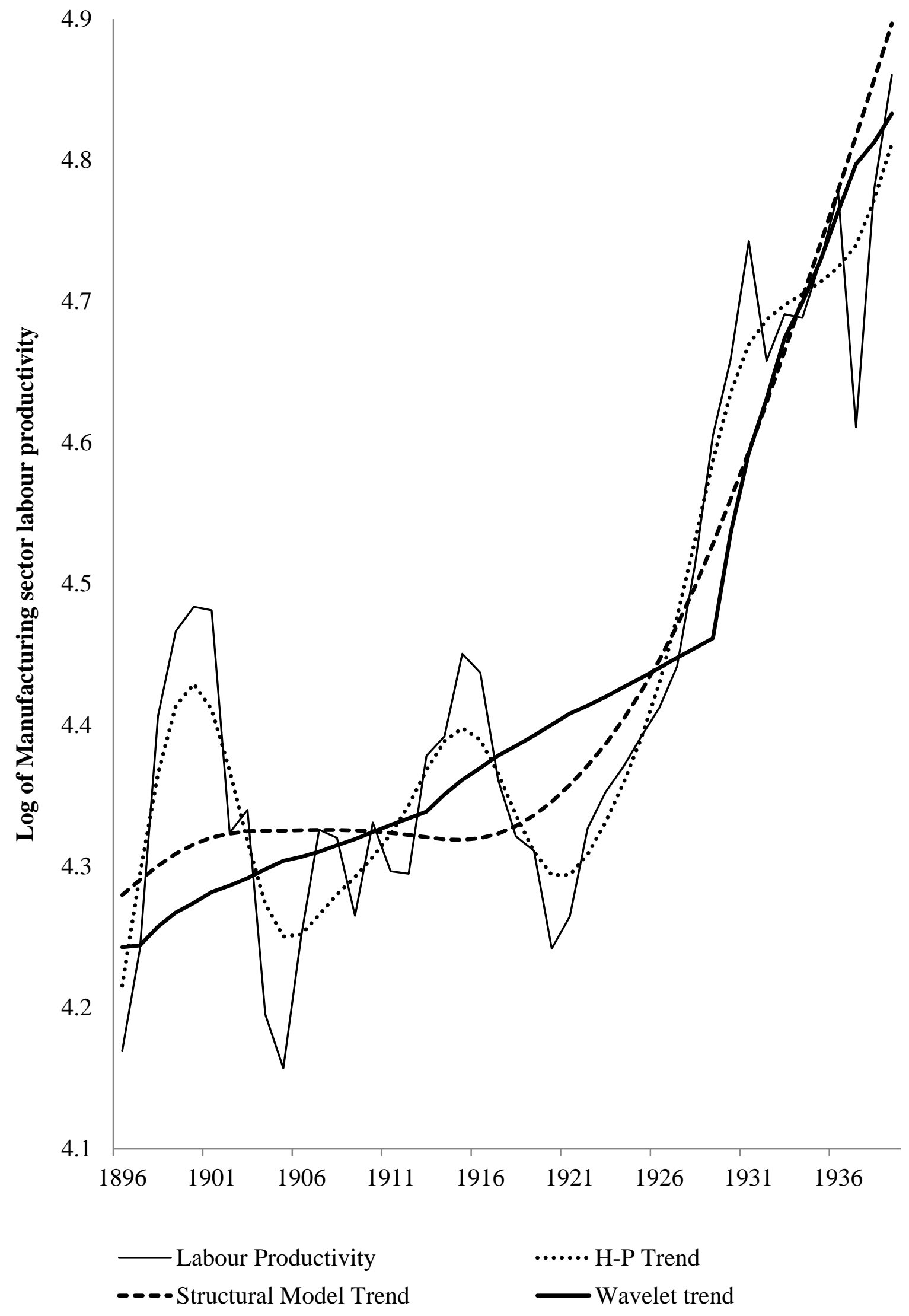


Figure 5 : German Manufacturing Sector

Labour Productivity 1875-1938

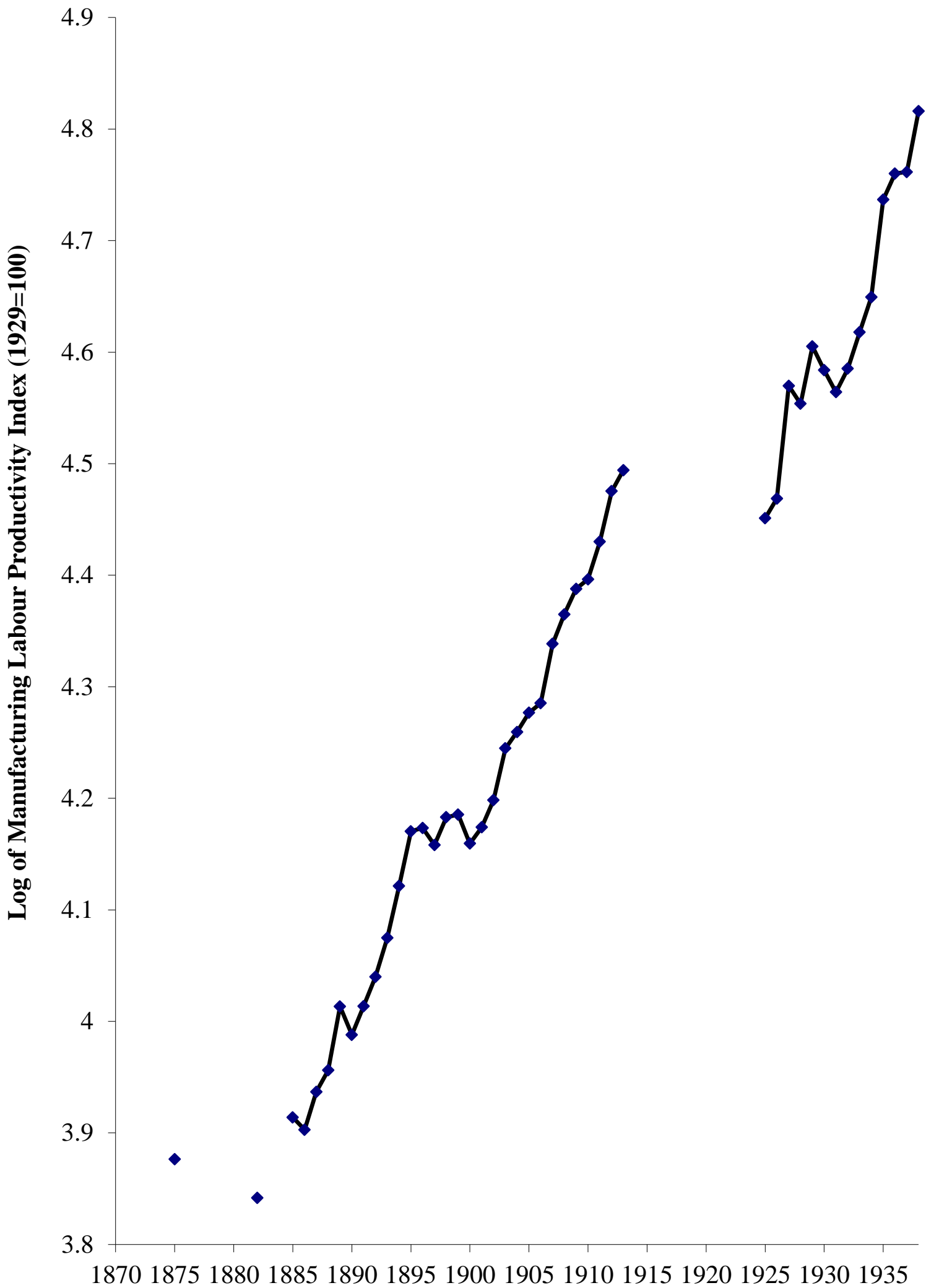


Figure 6: French Manufacturing sector Labour

Productivity Index 1921-1938

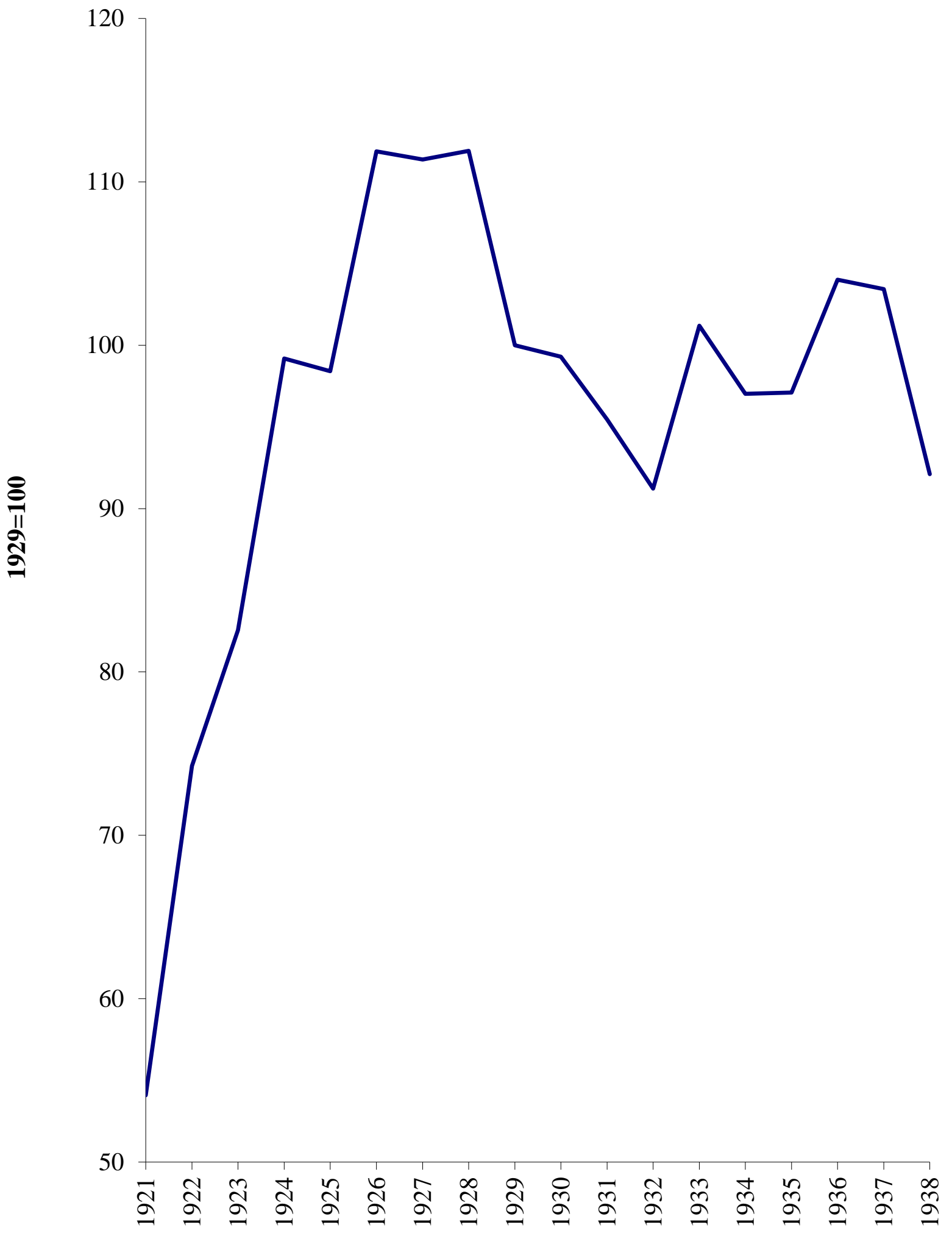

